\title{
Developing viable medical equipment, in general and for patient monitoring
}

\author{
D. J. W. TAYLOR \\ Medical Advisor, Supply Division, Department of Health \& Social Security, \\ 14 Russell Square, London, W.C.2.
}

\begin{abstract}
Summary
The importance of the relationship between demonstrable clinical advantage and total costs in the use of equipment, the role of the professional medical administrator in its development and the differences between the industrial and the ethical medical approaches to marketing are stressed.

In the final analysis routine service equipment should be assessed by actual profitability, recognizing the effects of philanthropic or research funding when it occurs.
\end{abstract}

\section{Introduction}

In this interdisciplinary medical and engineering discussion some two-fifths of those present are not medical and one-third come from industry. With this in mind these purely personal comments will attempt the difficult and often misunderstood task of introducing a base-line of reality in unspecialized terms.

By training and conditioning, pure research activities in any scientific field will, and should, always be attractive and respectable to the majority. But a few of those at the interface have to be concerned with the less popular but vital need for the development of equipment that may quite possibly have exciting new scientific features, but dominantly has to exhibit commercial viability. A design that meets the needs of the routine user, is also reliable, maintainable, available at a price allowing it to compete with its rivals and with other demands for funds, and that leads to profitable marketing, is viable in this context. Anything else is outside my remit and may also be outside the main interests of the majority here. Scientific, clinical or statistical debate in whatever detail that does not have equipment viability in mind as an ultimate goal could find a better forum.

In searching for such a viable product, hopefully to be sold at home and abroad, there is obviously no magic formula for success: it would be impertinent to suggest otherwise. But for those who might wish to explore the academic side of technical forecasting I would suggest starting with the paper by Coates (1969) from the Strathclyde conference. The burden of my argument is that any exercise must be very flexible and in the hands of the right type of committed professional experts working in small groups or, as we commonly call them, project teams.

The complexity of this task can be grossly underestimated by both clinicians and industry. Methods have to vary with the product, the time, and the wideranging varieties of customer structure. Much can be learned from drug industry practice, but the ordering of equipment is completely different from the repeated ordering of drugs, dressings, syringes or needles.

In my view lack of success with adventures into medical engineering cannot be primarily blamed on either:

the natural conservatism of the profession, the lack of technical insight by clinicians, or the shortage of funds, often said to be temporary. These views tend to come back second-hand from frustrated salesmen. What I think they reflect is the natural bed-side manner of the clinician, who if caught on his own doorstep at home by a washing machine salesman might have said more plainly,

we do not need one,

yours doesn't work well enough, we can't afford it.

Medical equipment marketing is very specialized and not at all like any other.

In this discussion let us deliberately exclude small run, highly specialized and rapidly changing hardware for the research laboratory or research ward, and appreciate that in the mass market we have as much to learn from the large number of general hospitals, as from the few undergraduate teaching hospitals.

There is an important place for the non-industrial medical engineering centre, supported at times by projects from industry or government. But at the end of the day the product has to come from industry. Just as an architect needs a firm client requirement while he designs and builds, industry has to identify generally acceptable requirements that will stand long enough to allow the design, prototype, production and marketing process. Industrial survival 
turns on timing and profit, and these are certainly not factors expected to be of first importance to the doctor or the non-industrial worker. Here lies the main challenge and in the interests of our economic health it deserves a wider appreciation.

\section{General development}

At one time, the creation of new surgical tools by individual surgeons and skilled craftsmen formed a major part of medical engineering development. Apart from metrication and other standardization problems, full use of present-day materials and fabrication knowledge would suggest a contribution in addition from the production engineer at least. But across the growing areas of general capability, the more complex the instrument and the more exotic the materials used, the easier is the case to make for a properly mounted executive and expert project team effort. The advisory committee operates at a different level of policy making rather than of execution of a project and thus has a quite separate role from that of the project team. Such different roles have at times been confused.

The need for discussion between working experts to produce just enough guidance to discourage wastage or anarchy, provide suitable objectives, set flexible targets, watch progress and call up other experts seems a matter of common sense. One can generalize from the new BMA Planning Unit Report (1969) on Computers that doctors must be incorporated in the project team from the very earliest stage, and that from all branches of medicine they participate both operationally and administratively. The medical administrative, as distinct from research or clinical, contribution deserves stressing and the methods adopted are well known to the professional medical administrators in the audience who have already acquired a significant national experience in overall hospital design. Such expertise is commonly overlooked or simply unrecognized in equipment, but not in ethical drug activities.

It is sad to observe the ease with which some research workers claim that their own project can readily be put into viable production. The difficulties of development are often unrealized and the overheads ignored. We saw this again at last year's Tenovus symposium on cytology automation (Taylor, 1970). The problem is long standing and international. In USSR, Babaev (1968) has discussed the importance within his system of team effort between researchers, designers and manufacturers. Springing originally from Strathclyde, Watson Watt and his radiolocation development team could still teach us lessons about limited objectives and optimization of effort.

We have also to recognize the occupational health, the environmental engineering and the safety of both attendants and patients, and we extend from this into human factors or ergonomics, and psychology. The valid interests to keep in mind are many, and because of the hospital environment and the assumed relative skill of the user, hospital equipment is often last to benefit from such experts or be embraced by available factory legislation.

At the Chicago meeting this summer, Caceres and Dickson were asking for more use of what technology already exists. This illustrates part of the interface communication problem discussed before (Taylor, 1968). Lenihan at Haifa in 1967 put it elegantly, 'A medical man has to take grave decisions on the basis of incomplete evidence, and must effect a compromise between intellectual precision and clinical urgency.' If he is a clinician he is trained to speak with individual confidence but this does not necessarily reflect any general authority outside the consulting room, although there are eminent clinicians who can do so. Clinical doctors may not always admit to the highly rarefied nature of their own experience and commercial understanding.

It is a matter of reaching the right selection and number of men and asking the right questions-as committed medical executives already full time in industry or health authority know well. Normally we would ask our solicitor to brief an appropriate barrister, or general practitioner to find the right consultant. There is a lesson here in opinion taking. Cutting out the proper and available channels may be faster, appear to be more efficient and incidentally gratifying to the individual, but can prove to be highly dangerous. Commercial enterprise obviously involves risk, but too many examples are known where investment in development and marketing has been poorly based, resulting in predictable loss. One can characterize this by thinking of the lone doctor that the industrialist happened to meet on the golfcourse as the only source of design or market information that the industrialist thought necessary to take.

Engineers are considered by Eden of MIT to be motivated to build (not necessarily usefully) and to deal with things that do not complain and can be ignored. They can also become emotionally involved. Also at Chicago, both from the chair and the floor, Wolff repeatedly asked 'But does it do anybody any good?' This is really the prime question to keep hammering in, or in other words, where is the medical evidence of demonstrable clinical advantage, a concept clearly stated in the Annual Report (1966) of the Chief Medical Officer.

We must also try and relate to the resources available, the total cost including marketing, maintenance and staffing, i.e. capital and revenue implications. New equipment often attracts more, not less staff. Professor Miller (1969) emphasizes that 'we 
shall never be able to provide everyone with every conceivable medical aid. The issue of priorities is inescapable.' Davis (1969) thinks we instinctively resist any tendency to think of a hospital as a business or an industry. But in any final analysis we are bound to recognize the broader rules.

Waddington (1969), has looked into the complexity of UK Research and Development activity comparing the relative investments in public and private sectors. We probably have an overall effort in medical equipment greater than we realize. In America the Harvard-MIT group with Johns Hopkins and others have just participated in the Committee on Interplay of Engineering with Biology and Medicine (1969) pilot study for the National Academy of Engineering.

Despite the overt publicity on television for new equipment, the spin-off from technology does not always have a clinical value. Telemetering selected signals from two fit men on the moon has great technical interest, but it does not necessarily follow that this has a benefit for routine monitoring of sick patients in a general hospital; even if it has some benefit is it worth the cost? There is nothing at all improper in the lobby supporting the advantages of space research. American doctors themselves have a healthy resistance to the non-clinically based engineering lobby, as we should have. The lobby is not really directed at the British taxpayer anyway, though equipment for mass screening is a special topic under active evolution and study.

The main hazard is that of the new technical device in search of a medical application. Quite competent calculating and electronic transmission devices have been with us for some time. We should, I suppose, be grateful that the computer sales engineers have brought various fairly well-established communication systems (albeit steadily improving) to the attention of a new untutored medical public. But is there any greater need now for these basic facilities than before? We have been looking for example at video tape and the possible transmission of X-rays over a TV link (Taylor, 1966). Fine bone detail can't be transmitted unless special magnification of suspect areas can be achieved, and the technique in several respects has really yet to establish itself. Medicine is experiencing much new jargon from amateur engineers about 'coaxial cables' and the like. There are certainly pioneering new projects in hospital communication being designed. But professional communication engineering, cable-route planning and signals traffic forecasting is not at all new.

To put this in perspective; FM transmission of analogue signals over line or radio has been with us as long as newspapers have sent pictures around the world. The teleprinter has transmitted trains of marks and spaces (or for that matter the nerve cell has fired or not fired), for considerably longer than the hospital world has been bombarded by binary digits.

There really has been a lot of capability around for a long time if medicine had really needed to use it. Let us not rediscover too many wheels even if the car has never been up a hospital drive before. Designing a new ambulance is a different matter.

There are highly systemized and detailed hospital planning techniques familiar to the administrators from the health service. One can relate some of the main stages in hospital design to equipment development in this way (see below).

As one refines prototypes into progressive production models, cyclical repetition is involved. Stages are dealt with as distinct and separate exercises possibly conducted in parallel but preferably completed in the order listed. Unlike the hospital, the equipment here is not intended as a 'one of'. For the manufacturer the exercise will not usually close with the hand-over, but involve some commitment to continued marketing and maintenance. Without becoming too obsessive about the method, on the professional side while the stages of equipment development $E, F$ and $G$ will be supervised technically, all the remainder have some concern to the medical administrator and he will conduct A, B and $\mathrm{H}$ at least. Care is needed to ensure that $\mathrm{E}$ is not conducted in isolation and that it meets $B$, or is amended only after full discussion. Changes in B after its completion are costly if not impossible.

As we continue to export some of our modern hospital designs, equipment is an important element. As Davies (1966) has explained, the Department of Health has important responsibilities to discharge as the production authority for the medical equipment

\section{SELECTED HOSPITAL PLANNING STAGES - EQUIVALENT STAGES IN EQUIPMENT DEVELOPMENT}

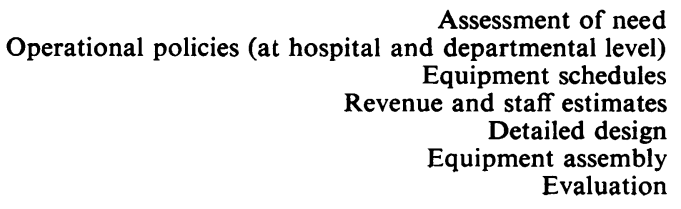

A. Identify demonstrable clinical advantage

B. User requirements (at all levels)

C. Quantify market needs (domestic and export)

D. Total cost implications (user and manufacturer)

E. Technical specification

F. Manufacture

G. Technical bench testing

H. Clinical Trial Organization 
industry and there is also the Department's new equipment research and development programme.

In practice, many of us become aware of the more common hazards to look out for concerning general service equipment seen from various viewpoints. Some of these can be summarized as follows.

\section{Hazards}

\section{For those concerned with general service equipment}

\section{At interdisciplinary meetings:}

a. Simple phenomena explained by repeated use of complex circuits or narrow jargon, meaningless to more than two-thirds of the audience (a real expert communicates effectively without use of a shield).

b. Attempted image building, perhaps unintentional, by over use of emotive terms from space or computer fields, or by misuse of others like 'cybernetics', a practice well punctured by Dunning (1968).

\section{For the non-medical:}

a. Not enough, or absent, medical or nursing opinion professionally collected, from the outset.

b. Real general service value hidden by research objectives or philanthropic backing.

\section{For the non-industrialist:}

a. Profit takers obscured between agents, assemblers, manufacturers, shareholders, associate companies and national agreements.

b. Commercial viability concealed by subsidy or free clinical trial.

c. Non-medical expressions of engineering intent, rather than ethical advertising which reports actual clinical trial experience, published by clinicians and thus open to professional debate.

\section{For the industrialist:}

a. Clinical expressions of polite or research interest as distinct from ability to cause purchase.

b. Inconsistency of purchasing structure between each item.

c. Unappreciated difference between quite separate skills brought to industry by medical employees from research, clinical or administrative backgrounds.

d. Poor communication between Research and Development and other divisions in the same organization of any type and at any level.

\section{Patient monitoring}

Looking at patient monitoring in particular, it is easy to forget that an engineer often uses the most complex and interesting techniques to monitor and control engineering processes which although adequate for their own purposes, when compared with physiological systems, may be relatively very simple. In patients, monitoring may only indicate in a poor way very few superficial and available parameters giving most crude approximations to the infinite complexity of patient well-being. Apparently simple things for human attendants to recognize can turn out to be impossibly complex for the machine, as we know very well from our adventures in pattern recognition by machine, rather than human, sensing. The human computer is still fairly good at filtering the signal from the noise involved economically, the machine is not always as good.

The intelligent American has long since had to learn to resist his own type of mass marketing and interpret the journalistic out-pourings from his mass media. This is something we might appreciate more widely here with our softer selling and more polite reaction. Over there a healthy cynicism is detectable about the value of computers. In this country we seem to be well-alerted to the undoubted long-term potential but may sometimes in our first reactions, while assessing clinical value, be more gullible, or simply a stage behind the Americans. Realistically the new BMA Planning Unit Report (1969) on computers reminds us that automatic diagnosis is one of the most persistent images of computer applications in medicine, yet it is still a remote and possibly impracticable dream. In this report's introduction, Professor Miller adds that only an experienced observer can register that the patient both looks and is seriously ill. In this context it would be fair to distinguish the final analysis from the individual diagnostic parameter or diagnostic aid.

Industry knows that innovation dare not be stifled. Writing in Science Journal, Professor Miller (1969) emphasizes that research depends on curiosity and enthusiasm which are blunted by direction. But although service equipment will arise from research equipment it is important to separate these areas. Clinical trials of service equipment must have practical implications in mind. Rawles \& Crockett (1969) have just reported such a trial of patient monitoring equipment and it is refreshing to read about their particular general ward situation that

'greater benefits would have resulted for these same patients if the money used to purchase this equipment had been spent on simple oscilloscope ECG displays and the provision of more nurses for continuous surveillance of ill patients.'

Another approach to assisting viable development is to try and set down the lowest common denominator on which investment and production for the mass market might turn. It might appear superficially to result in a simple statement of the obvious, but those with experience know that it can be very difficult to set down. Actually stating a view that might have general acceptability has its own value, and it can help formulate other quantitative views when equipment notes are drafted or equipment lists assessed. Obvious or not, current industrial offering 
suggests that many of such basic requirements need clear statement and frequent repetition.

Patient monitoring in the general hospital

Extract of outline user requirements-basic transportable monitor

1. General requirements:

a. Used generally in ward, intensive care, theatre and other areas.

b. Reasonably small and lightweight, rugged transportable, standard, simple, cheap, reliable, minimum controls, modular construction allowing 'add on' units.

2. Special requirements:

a. BASIC MODULE

i Two electrode input and earth.

ii Simple ECG amplifier.

iii CRO display on 5-inch screen adequate-or

iv Larger TV raster display acceptable if as viable.

v Controls 'ON/OFF' and 'SENSITIVITY'.

vi Automatic brightness.

vii Standard in/output jacks.

viii Standard interface characteristics for local and remote connection to other modules and processors.

b. OPTIONAL MODULES

i Heart rate meter display.

ii 'Bleep' or 'Flash' display.

iii Heat stylus recording.

iv Temperature display.

v High/low alarms (low priority).

c. LESS ESSENTIAL FACILITIES

i Automatic centring.

ii Storage tube display.

\section{Conclusion}

In the face of many exciting adventures into the possible future described at this meeting, my task has been to set a base-line of reality concerning the actual, the achievable, the available and viable equipment used today in the majority of general hospitals. For some years the British Institute of Management in its journal (Winsbury, 1966), has quoted the need for ruthless attention to the likely pay-off of all our research and development. They also emphasize that unless our efforts are directed by people whose basic aim is national survival then we are for it.

Professor Miller (1969) says that the snobbish distinction between pure and applied science is no longer relevant. I have always thought that this has had some relationship to the poor professional status of the engineer and of other professionals outside the laboratory in this country. Certainly the luxury of over much pure research for its own sake is difficult for us to support unless we can at the same time effectively drive more of our discoveries right through to the point of profit taking. Anything less is surely non-viable or plain failure.

As in America and Russia, there are signs that research and development here is under intensifying scrutiny. Medical equipment merely forms a very small part of this, but it is our only concern. For some years there has been the challenge facing doctors that no matter what diagnostic or therapeutic speciality we choose to follow, it is increasingly difficult for those who take refuge in medicine hoping to avoid mathematics or technology. For all of us of whatever discipline or interest, adaption from older concepts and attitudes seems more important than ever if our equipment is to be really viable.

\section{References}

Annual Report of the Chief Medical Officer for the year 1965 (1966) On the State of the Public Health, p. 197, HMSO, London.

BabaEv, B.S. (1968) Some problems connected with the development and production of medical instruments and apparatus. Meditsinskaya Teckhnika, 4, 5.

COATES, D.R. (1969) Technological forecasting and the planning of R. \& D. Technological Forecasting. Proceedings of University of Strathclyde Conference, Glasgow 1968, p. 83. University Press, Edinburgh.

Committee on interplay of Engineering with Biology and Medicine (1969) Prototype University Plans for the Development of Biomedical Engineering, p. 14. National Academy of Engineering, Washington.

Davies, S.M. (1966) Government and the medical supplies industry. British Hospitals, p. 19. Trafalgar Press, London.

Davis, J.F. (1969) The hospital-a different kind of business. Medical and Biological Engineering, 7, 257.

DunNing, G. (1968) An explanation of some mysterious management terms being used in hospitals. Hospital World, $7,1$.

Miller, H. (1969) Real goals for medicine. Science Journal, 5a (No. 4), 90.

Planning Unit Report No. 3 (1969) Computers in Medicine, p. 4, 27, 50. British Medical Association, London.

RAwles, J.M. \& CrocketT, G.S. (1969) Automation on a general medical ward, British Medical Journal, 3, 707.

TAYLOR, D.J.W. (1966) Tape recording (video) in hospitals. World Medical Electronics. Proceedings of First European Symposium on Medical Electronics, Brighton 1965, 4 (No. 1), 29.

TAYLOR, D.J.W. (1968) The medical engineering interface in Britain. Instrumentation in Medicine. Proceedings of Second European Symposium on medical electronics, London 1967, p. 74. Hanover Press, London.

TAYLOR, D.J.W. (1970). Discussion of day's proceedings. Cytology Automation. Proceedings of Second Tenovus Symposium, Cardiff 1968, p. 136. Livingstone, Edinburgh.

Waddington, C.H. (1969) Assessing the priorities. Science Journal, 5a (No. 4), 106.

WinsBURY, R. (1966) The interface controversy. Management Today, November, p. 62. 